you the earnest wish of all members here present that you may be preserved in health, and may be enabled to carry on your work to a successful termination."

\title{
The Advisory Committee on the Care of the Blind
}

On p. 627 (Vol. 1) we gave a résumé of the excellent report of the Departmental Committee of the Local Government Board on the Welfare of the Blind. The President of the Board, the Right Hon. W. Hayes Fisher, has now appointed an Advisory Committee to advise the Department. The following members have been appointed:-Mr. Stephen Walsh, M.P., Parliamentary Secretary to the Local Government Board (chairman), Mr. Henry J. Wilson (vice-chairman), Miss E. W. Austin, Mr. Guy M. Campbell, Mr. P. M. Evans, Mr. Charles Hartley, Mr. G. F. Mowatt, Mr. Alexander Pearson, Sir Arthur Pearson, Mrs. Wilton Phipps, Mr. Miles Priestley, Mr. Ben Purse, Mr. Henry Stainsby, Mr. W. H. Thurman, and Mr. H. C. Warrilow. Mr. E. D. Macgregor, of the Local Government Board, will act as secretary of the Committee. Most of these ladies and gentlemen have had great experience in the management and training of the blind, and no exception can be taken to them. There is, however, an important omission: there is no ophthalmic surgeon or medical representative. The following correspondence has recently appeared in The Times :-

\section{THE CARE OF THE BLIND.}

\section{To the Editor of The Times.}

Sir,-In your issue of Saturday the 8th there appeared a list of the names of the Committee appointed by Mr. Hayes Fisher to advise the Local Government Board on matters relating to the care and supervision of the blind. I should have thought it was a proposition requiring no argument to support it that on such a Committee there would be at the very least one ophthalmic surgeon, but there is not even a single medical man. I was a member of the Sub-Committee appointed by the Royal Society of Medicine to draw up a definition of what should be considered blindness for the purpose of the Act, and I had a good deal to do with the actual drafting of the report made to the Departmental Committee on the Welfare of the Blind. This report was accepted without modification by the Committee, and on it is based their definition of blindness. I know something of the difficulties the Committee will have to face in applying the definition. Yet there is not a single person on that Cornmittee with the expert knowledge of blindness and its causes to give advice. Further, such a Committee will have unrivalled opportunities of gaining statistical information as to the 
causation of blindness which should prove invaluable in any future regulations for dealing with preventible blindness. Ophthalmic surgeons know only too well how great is the proportion of cases where blindness could have been prevented by timely measures.

The Royal Society of Medicine, whose sub-committee drew up the original report on the definition of blindness, or the Ophthalmological Society of the United Kingdom would have willingly nominated one or two ophthalmic surgeons to act, and I would respectfully suggest to the President of the Local Government Board that he should approach one or other of those bodies and ask them to nominate two ophthalmic surgeons to serve on this Committee.

I am, \&c.,

Ophthalmic Surgeon.

HARLEY STREET December 9.

Sir,-The letter signed by "Ophthalmic Surgeon" which appeared in to-day's issue of The Times demands, I think, some answer from me. My reason for not inviting an ophthalmic specialist to become a member of the Committee which I have set up to advise my Department on matters relating to the blind is that in all probability nine-tenths of the Committee's time will be taken up with consideration of administrative problems. I felt, therefore, that under existing conditions it would not be right to make a further demand upon the time of any of our eminent ophthalmic specialists, who are already so fully occupied. I need hardly say that in coming to this decision I was guided by the consideration that the Advisory Committee, in the investigation of medical aspects of the problem, would always have at their disposal the ready and generous assistance of individual members. of the profession and of the Royal Society of Medicine and the Ophthalmological Society of the United Kingdom. It is merely a question of how that assistance can best be rendered.

Yours truly,

W. Hayes Fisher.

Local Government Board, Whitehall. December 10.

Sir,-Mr. Hayes Fisher in his letter to-day seems to admit fully my contention of the need for expert assistance on the Committee for the Welfare of the Blind, and ends by saying, "it is merely a question of how that assistance can best be rendered." I consider that it is a question not of " how," but of "when," and that the best time is when the regulations are being drawn up. Not nine-tenths of the time of the Committee will be devoted to administrative 
problems, but the whole of its time, as its function is to advise on the administration of the Act; but nine-tenths of the administrative problems with which it has to deal will touch on subjects in which the knowledge of the expert ophthalmic surgeon is required. I feel sure that if Mr. Hayes Fisher had not been so tender in his consideration for the hard-worked ophthalmic specialist and had himself trespassed on the time of any one of them for half an hour they could have adduced evidence sufficient to convince him of the need of constant and primary expert assistance on such a committee rather than intermittent and secondary.

Yours, \&c.,

OphTHALMIC SURGEON.

HARLEy STREeT,

December 11 .

It may be mentioned that the original Departmental Committee had three medical men upon it, one of whom was an ophthalmic surgeon, Mr. Harold B. Grimsdale. This Committee invited the Royal Society of Medicine to assist them in their deliberations and a subcommittee of the Section of Ophthalmology devoted much time and attention to the subject. The Report shows that full use was made of their labours. In the ordinary affairs of civil life it would not be thought courteous to obtain the gratuitous services of experts and then proceed to put their recommendations into action without inviting their co-operation. "Under existing circumstances" there may still be ophthalmic surgeons, whose offers to the War Office have not been accepted-have, indeed, often been entirely ignored-and who are sufficiently free to undertake other duties. In any case, they themselves are the best judges of the time which they have at their disposal, and Mr. Hayes Fisher's polite excuses serve but to accuse him of consistency with the pernicious traditions of Government officials.

\section{A National Ophthalmological Advisory Committee}

In an annotation contained in the BRITISH JOURNAL OF OPHTHALMOLOGY of November (p. 678), the suggestion was made that all problems having an ophthalmological bearing arising in any of the Government departments should be referred to a standing advisory committee composed of ophthalmic surgeons. In the present number we publish the report of the Committee of the Ophthalmological Society on Standards of Vision, which includes their correspondence with the War Office, and in the previous annotation we draw attention to the appointment of an Advisory Committee of the Local Government Board on the care of the blind. In both cases we regard the official 